International Journal of Biomedicine | June 2021 - Volume 11, Issue Suppl_1: Abstracts from the Third Russian International Conference "Cryo-electron microscopy 2021: achievements and prospects"

POSTER ABSTRACT PRESENTATIONS

SESSION TITLE: STRUCTURE OF MEMBRANE PROTEINS

DOI: 10.21103/IJBM.11.Suppl_1.P10

\title{
Abstract P-10: Solvatochromic Fluorescent Dyes Tested for Spectroscopic Measurements of Protein Conformational Dynamics
}

$\underline{\text { Anatolii Belousov }}^{1}$, Ivan Maslov ${ }^{1}$, Polina Khorn ${ }^{1}$, Alexander Mishin ${ }^{2}$, Mikhail Baranov $^{2}$, Thomas Gensch ${ }^{3}$, Valentin Borshchevskiy ${ }^{1,3}$

${ }^{I}$ Moscow Institute of Physics and Technology, Dolgoprudny, Russia ${ }^{2}$ Shemyakin-Ovchinnikov Institute of Bioorganic Chemistry, Russian Academy of Sciences, Moscow, Russia ${ }^{3}$ Forschungszentrum Jülich, Jülich, Germany

Background: Recoverin is a $23 \mathrm{kDa}$ protein, belonging to the superfamily of EF-hand $\mathrm{Ca}^{2+}$-binding proteins. One of the functions of recoverin is to regulate the activity of the rhodopsin kinase GRK1, which regulates the activity of rhodopsin. In dim ambient light, the level of calcium in the rod cells of the retina is high, so recoverin binds to and inhibits rhodopsin kinase, leaving rhodopsin very sensitive to photons to enable the eye to detect visual signals even under low-light conditions. Many biophysical methods have previously been used to study the conformational dynamics of recoverin, including NMR, SPR and fluorescence spectroscopy. Here we describe fluorescent solvatochromic dyes suitable for spectroscopic observation of conformational changes in recoverin.

Methods: We tested four fluorescent dyes, which were covalently attached to Cys39 of recoverin via the thiol-maleimide interaction.

Results: Two out of four labeled recoverin samples showed EGTA-induced changes in the fluorescence lifetime and excitation and emission spectra.

Conclusion: Our experiments show solvatochromic fluorescent dyes that can be successfully used for spectroscopic observation of conformational dynamics in proteins.

Key Words: EF-hand protein • spectroscopy $\bullet$ fluorescent solvatochromic dyes 
This work was supported by the Russian Foundation for Basic Research (Grant No. 20-34-70034)

*Corresponding author: Anatoly Belousov.E-mail: belousov.as@phystech.edu

International Journal of Biomedicine. 2021;11 Suppl 1: S15.

doi: 10.21103/IJBM.11.Suppl_1.P10

(C)2021 International Medical Research and Development Corporation 